\title{
Study of Haemocytes of the Rice Brown Planthopper, Nilaparvata lugens Stål (Hemiptera: Delphacidae)
}

\author{
Amani Mannakkara* \\ Received: 06 ${ }^{\text {th }}$ February 2021 / Accepted: 06 $6^{\text {th }}$ November 2021
}

\begin{abstract}
Purpose: The brown planthopper (BPH), Nilaparvata lugens, is one of the most serious insect pests of rice (Oryza sativa L.) in South and South East Asia and also parts of the Pacific and Australia. The BPH, like other insects, is able to build up powerful innate immune responses against invading pathogens and cellular immunity mediated by haemocytes. Hence, an attempt was made to investigate the detailed microscopic analysis of the haemocytes of $B P H$.
\end{abstract}

Research Method: The study was primarily concerned with the haemocyte profile of BPH with emphasis on the changes in the total and differential haemocyte population with three different life stages; 5th nympal stadium, newly emerged adults (post-moulting adult of 1-3 days old) and matured adults (15 days old) for an insight of the physiological events during the morphogenesis.

Findings: According to light microscopic examinations, the haemogram of the BPH comprised six types of haemocytes viz. prohaemocytes (PRs), plasmatocytes (PLs), granulocytes (GRs), adipohaemocyte (ADs) oenocytoids (OEs) and spherulocytes (SPS). It was estimated that the mean numbers of total haemocyte count are varied from 6096.4 to 7393.6 cells per mm3 of haemolymph with the different physiological stages of the insects and it was statistically increased in the mature adults. PLs, GRs and PRs are the most abundant cells in the haemolymph in all development stages of BPH while SPs is the scarcest type.

Originality/value: To our knowledge, this is the first report that has detected the haemogram of BPH and these data are valuable for future avenues of immunological research of $B P H$.

Keywords: Differential haemocyte count, Haemocyte profile, Total haemocyte count

\section{INTRODUCTION}

Insects have to depend on innate immunity which is consisted of humoral and cellular components, to counteract themselves from infections and invasions (Ratcliffe et al., 1985; Lavine and Strand, 2002; Gupta et al., 2005; de Andrade et al., 2010; Mangalika et al., 2010). Humoral immunity involves induced antimicrobial peptides and other immune-related molecules generated by fat body and haemocyte that regulate extracellular and intracellular signal transduction which leads to induce melanization and clotting to immobilize and/or kill invading foreign bodies (Lavine and Strand, 2002; Kanost et al., 2004; Shrestha et al., 2010; Wang et al., 2011). Cellular defense involves with haemocyte-mediated immune responses such as phagocytosis, nodulation and encapsulation that are mainly mediated by the interaction of haemocytes (Lavine and Strand, 2002; Jiravanichpaisal et al., 2006; Wang et al., 2011). Other than the immune reactions, haemocytes have multiple functions such as wound repair and coagulation to prevent loss of blood (Lai et al., 2001; Rowley and Powell 2007; Cerenius and Soderhall, 2011),

\footnotetext{
* Department of Agricultural Biology, Faculty of Agriculture, University of Ruhuna, Kamburupitiya 81100, Sri Lanka. amani@agbio.ruh.ac.lk

(D) https://orcid.org/0000-0002-3457-9781
} 
direct nutrients storage them (Meloni et al., 1999; Pandey et al., 2010; Pandey and Tiwari, 2012), transporting hormones (Meloni et al., 1999; Pandey et al., 2010; Pandey and Tiwari, 2012), detoxification of metabolites and biological active materials (Patton, 1961; Qamar and Jamal 2009), etc. Therefore, haemocytes endowed with a wide variety of physiological, biochemical and immunological functions of insects.

Haemocytes have been studied mostly in Lepidoptera, Hymenoptera, Coleoptera, and Diptera(Gupta, 1985). Thehaemocytes, circulating in the haemocoel of insects are categorized into several types by their morphology, functions, and staining or histochemical reactions, but, clear guidelines for classification of these cells are still lacking. The most common types of haemocytes in various insect orders are prohaemocytes (PRs), plasmatocytes (PLs), granulocytes (GRs), spherulocytes (SPs), adipohaemocytes (ADs), and oenocytoids (OEs) (Lavine and Strand, 2002) and their characteristics slightly differ across various insect species (Ribeiro and Brehelin, 2006).

The brown planthopper (BPH) Nilaparvata lugens, is one of the most important sap sucking insect pests of rice, causing huge economic damage to the rice production, directly by feeding and also indirectly by transmitting viruses (Dyck and Thomas, 1979; Win et al., 2011). Opposite to the economic importance of this insect pest, little or no work has been carried out on the BPH haemocytes. The present study was primarily concerned with the haemocyte profile of the BPH with emphasis on the changes in the total and differential haemocyte population across three different life stages: $5^{\text {th }}$ nympal stadium, newly emerged adults (post-moulting adult of 1-3 days old) and aged adults (15 days old) for an insight of the physiological events during development.

\section{MATERIALS AND METHODS}

\section{Experimental Insects}

Initially, the BPH population collected from farmer paddy fields were reared in cages $\left(2^{\prime} \times 2^{\prime} \times 3^{\prime}\right)$ having aluminium frames and fine- mesh nylon sidewalls under room temperature at day light conditions at least for one generation. Two-month-old potted rice plants of variety $\mathrm{Bg}$ 380 were used to feed the insects and these potted plants were replaced by new ones as necessary. Enough numbers of newly emerged adults were transferred to another cage and maintained 15 days to obtain mature insects for experiments. Fifth nymphal stadium and newly emerged adults were collected directly form the original cages. While the population of BPH consists of both brachypterous and macropterous, only macropterous morph was used for the experiment. We studied both sexes separately in adult stages except the nymphal stage. All individuals used for the experiment were randomly selected.

\section{Haemocyte Morphotypes: Observation of Haemocytes on Stained Haemolymph Smears}

Newly emerged adult female BPHs were used to study the morphotypes of haemocytes. To collect haemolymph from each insect, one front leg was cut in midway and allows a small bead of hemolymph placed on a glass slide. Pooled samples of haemolymph from 5 insects were used to prepare one slide. Thereafter, the slide was air-dried for 2-3 minutes and fixed with $100 \%$ methanol at $4 \mathrm{C}$ for 5 minutes. Before sample collection, the insects were anaesthetized by slow cooling on ice to facilitate an easy handling of insects. Haemocytes were then stained with few drops of Giemsa dye for 2-5 minutes for morphological examination. Finally, Smears were washed with running distilled water until dye residues disappeared and cover-slip was mounted on a glass slide with a commercial aqueous mounting medium. These smears were observed under a light microscope and types of hemocytes in BPH hemolymph were described with shape, size, nuclear/cytoplasmic ratio, staining reactions and position of the nucleus. Haemocyte morphotypes were classified using previously established morphological criteria and terminology with special emphasis on Jones' classification (Jones, 1962; Price \& Ratcliffe, 1974; Brehelin et al., 1978; Gupta, 1979a; Gupta, 1994; Lavin \& Strand, 2002; Ribeiro \& Brehelin, 
2006; Stand, 2008). Photographs were taken with NIKON camera which was connected to the microscope and images were captured. Size of each type of haemocytes $(n=10)$ was measured using the same software.

\section{Haemocyte Morphotypes: Observation of Haemocytes Immediately after Bleeding}

As well, haemolymph samples were observed immediately after bleeding to view live. For that, haemolymph were dropped directly on the glass side and cover-slip was mounted immediately (Barracco \& Cestari, 1984; Hillyer $\&$ Christensen, 2002). These slides were observed under light microscope and digital images were captured connected to a colour digital NIKON camera. Structural changes of hemocytes during incubation were observed for 60 minutes.

\section{Differential Haemocyte Count}

Insects at $5^{\text {th }}$ nymphal stadium, newly emerged adult stage (1-3 day old adults) and aged adult stage(15 days old) were used to determine the differential haemocyte count (DHC) using the hanging-drop technique (Gupta, 1979b; Gupta, 1979c). Hemolymph was drawn directly into the drop of 0.1 M PBS (pH 7.2) on glass cover-slip after cutting off one front leg in the midway with gentle abdominal pressure from anaesthetized insects at different age groups separately. Then, the cover-slip was set in a humid chamber and haemocytes were allowed to spread and adhere to glass surfaces for 5 minutes at room temperature. Thereafter, the cover-slip was removed from the chamber and carefully turned upside down and placed it over the cavity slide. Finally, the edges of the cover-slip to the slide were sealed with colorless, transparent nail polish. Due to the small size of insects, the hemolymph from 5-10 individuals was pooled to prepare one slide. For each age category of the insects, 5 slides were prepared. Two hundred cells were counted per slide using the random sampling method using light microscope.

\section{Total Haemocyte Count}

Total haemocyte count (THC) was determined in three different age categories; 5th stadium nymphs, newly emerged adult stage (1-3 day old adults) and aged adult stages (15 days old). Haemolymph was collected after cutting off one front leg in the midway of cooled anaesthetized insects with gentle abdominal pressure to a glass micro-capillary tube as it pearled from the wound. A total of $2-10 \mu 1$ of hemolymph was collected from 50 to 200 individuals and immediately transferred into the $1.5 \mathrm{ml}$ Eppendorf tube containing $0.1 \mathrm{M}, \mathrm{pH} 7.2$ phosphate buffer solution in a proportion of $1 \mu$ l of hemolymph to the $9 \mu \mathrm{l}$ of buffer solution. After mixing by gentle pipetting, one drop of haemolymph was mounted near the edge of the cover slip of the Neubauer haemocytometer to facilitate to automatically fill the entire chamber by capillary action. After allowing several minutes to settle down the haemocytes, the haemocytes were counted in four corners and central ruled squares in each of the two chambers of haemocytometer under a microscope (Jones, 1962). Each was replicated five times. The number of circulating hemocytes per cubic millimeter $\left(\mathrm{mm}^{3}\right)$ was computed by using the formula suggested by Jones (1962).

\section{Statistical Analysis}

The differential haemocyte count and total haemocyte count were analyzed by one-way analysis of variance using SPSS 18 for Windows (SPSS Inc.).

\section{RESULTS AND DISCUSSION}

\section{Morphological Observations}

The examination of the haemocytes from $\mathrm{BPH}$ indicates the presence of six (6) types of haemocytes: PRs, PLs, GRs, ADs, OEs and SPs were morphologically distinct using light microscope (Figure 01) with different percentages at different physiological stage of BPH (Figure 02). 


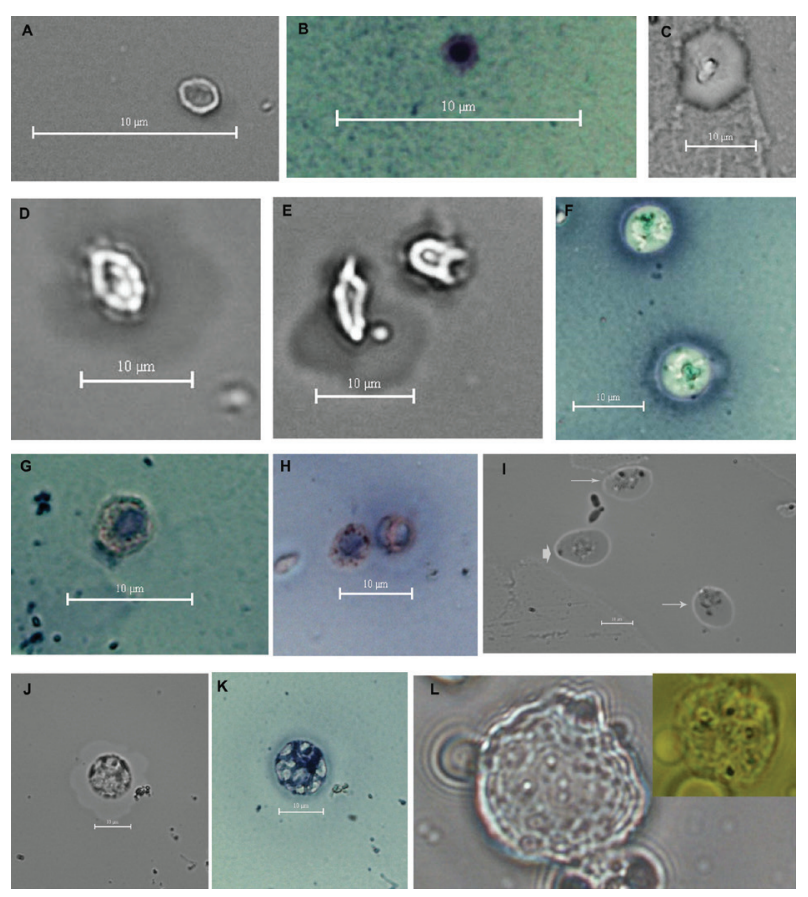

Figure 01. Light micrographs of haemolymph smear of BPH showing different types of haemopcytes (A) PRs. The nucleus occupies a large part of the cytoplasm, (B) PRs stained with Giemsa; the cytoplasm is with acidophilic characteristics and basophilic nucleus (under oil immersion x 100 using light microscope). (C) Round plasmatocyte (D) and (E) Fusiform plasmatocytes. (F) Round plasmatocyte (stained with Giemsa; note nucleus with basophilic characteristics $(40 \times))$. (G and H) GRs. stained with Giemsa (40×). (I) OEs with exocentric nucleus (thin arrow) and central nucleus (broad arrow) $(40 \times)$. (J) ADs without Giemsa staining $(40 \times)$. (K)ADs stained with Giemsa $(40 \times)$, (L) SPS observed in wet smears with the light microscope $(40 \times)$.

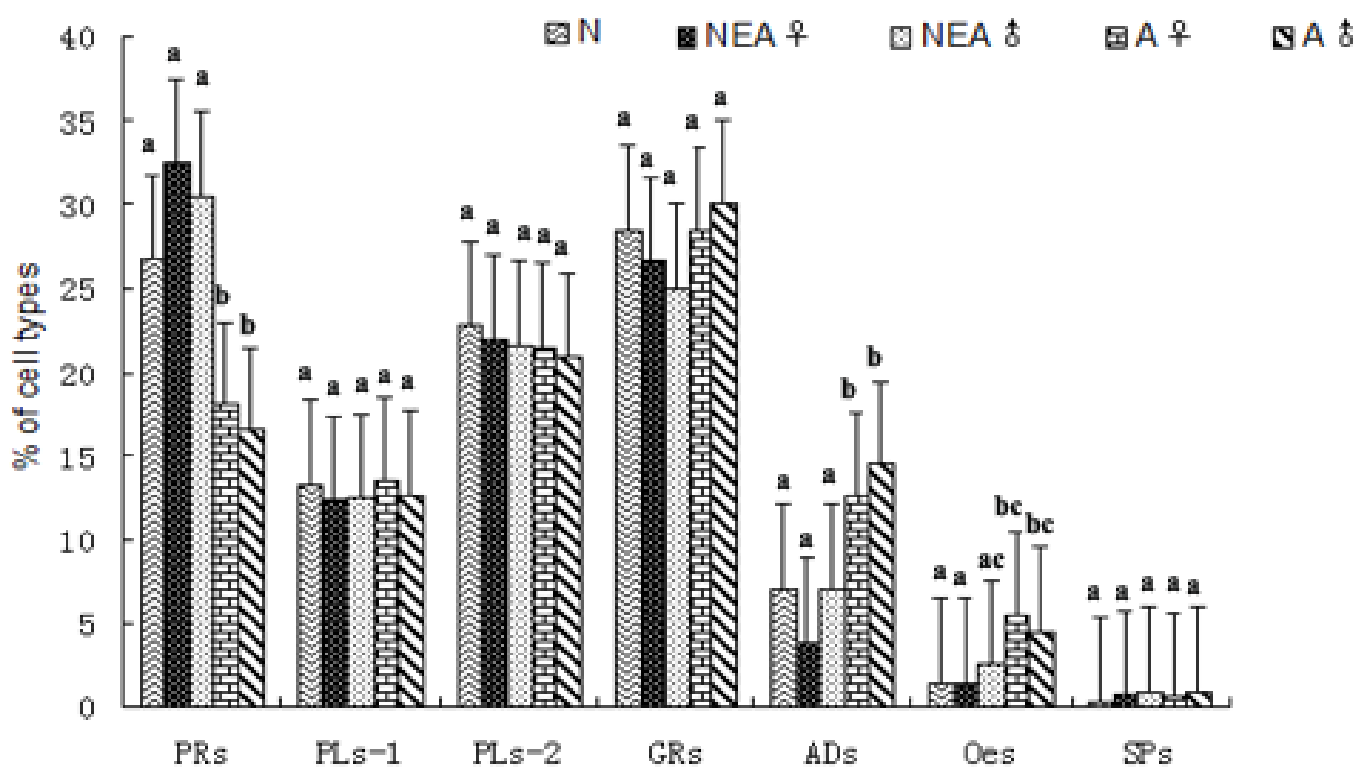

Figure 02: Percentage of different type of hemocytes of Rice brown plant hopper; Nilaparvata lugens Stål (Hemiptera: Delphacidae) at the different physiological stages. Randomly selected 200 cells/slide were assessed for calculate the percentage of different types of cells. Pooled samples of haemolymph from 5-10 insects were used to prepare one slide. PLs-1 - Round shape PLs; PLs-2 - Fusiform shape PLs; N - Nymph; NEA $q$ - Newly emerged Adult $q$;

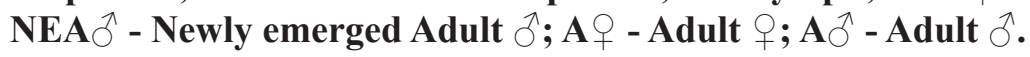




\section{Prohaemocytes}

PRs are small, round cells with variable sizes (0.5-3 $\mu \mathrm{m}$, average of $1.5 \mu \mathrm{m})$. The centrally located nucleus is larger and almost fills the cell containing high nuclear/cytoplasmic ratio (Figure 01(A)). With Giemsa staining, cytoplasm stained with an acidophilic characters and the nucleus exhibited basophilic affinity (Figure 01(B)). In monolayer, most prohaemocytes remained unchanged within the 60 minutes incubation experimental time period at room temperature $\left(25^{\circ} \mathrm{C}\right)$.

\section{Plasmatocytes}

Plasmatocytes are the most abundant cell type present. These are polymorphic cells of variable sizes measuring approximately 5 - 15 $\mu \mathrm{m}$ in diameter. The round or elongate nucleus is commonly located in the central of the cell (Figure 01 (C), exocentric nucleus was observed rarely. The cytoplasm is abundant containing low nuclear/cytoplasmic ratio. Cytoplasm softly stained in a light grey and the nucleus appears paler blue with Giemsa staining (Figure 01F). These cells started to form surface projections (pseudopodia) after 5-10 minutes of bleeding and completed these changes after 30 minutes of bleeding at $25^{\circ} \mathrm{C}$. Being polymorphic, two distinct forms of plasmatocytes were observed for the round shape plasmatocyte (Figure $01 \mathrm{C}, \mathrm{F}$ ) and fusiform shape plasmatocytes (Figure 01 D,E). Fusiform shape plasmatocytes were more common in all the tested age categories than round shaped ones ranging $61 \%$ to $64 \%$ among different physiological life stages from whole plasmatocytes population.

\section{Granulocytes}

Granulocytes are the second most common cell type with round or ovoid cells of variable sizes $(3-9 \mu \mathrm{m})$. The relatively small, rounded or elongate nucleus is generally located in the cell center, exocentric nucleus was observed rarely. The cytoplasm characteristically consists of numerous small granules. The nuclear chromatin appears as blue and the cytoplasm stains up pale pink after Giemsa staining (Figure-1(G-H)). In monolayer, after few minutes of incubation, granulocytes were readily attached to glass and begun to spread out on the glass surface. These cells spread on the glass surface forming large and thin cells reaching diameters that may exceed $10 \mu \mathrm{m}$ and completed the spreading fully within 35 minutes of incubation at $25^{\circ} \mathrm{C}$. After about 15 minutes of incubation the initial refractiveness of the cells became declined due to gradual lose of cytoplasmic granules. Most of the cytoplasmic granules were disappeared and cells gradually lose their initial refractiveness within the incubation period. At the 60 minuets incubation time period, these cells did not form any surface projections (pseudopodia).

\section{Oenocytoids}

Oenocytoids are large cells $(15-35 \mu \mathrm{m})$ with round or ovoid in shape that measure approximately 15 - $35 \mu \mathrm{m}$ in diameter. They contain large, often eccentrically positioned nucleus. The cytoplasm is abundant containing a low nuclear/cytoplasmic ratio (Figure-(I)). These cells are characteristic by rapid lysis. Immediately, after bleeding, these cells were shown to have very smooth surface and without any cytoplasmic extensions. These cells started to lysis within 5-10 minutes after bleeding and completely lysed within $10-15$ minutes at $25^{\circ} \mathrm{C}$. These hemocytes were observed very rarely with Giemsa stain technique.

\section{Adipohaemocyte}

These are oval cells with $10-15 \mu \mathrm{m}$ length. Compared with that of the plasmatocytes, the nucleus is relatively small, elongate and is mostly eccentrically located. The cytoplasm is abundant containing a low nuclear/cytoplasmic ratio. Several large lipid droplets are seen in the cytoplasm (Figure-1(J-K)). Light microscopic observations did not show any morphological changes on the cells during the incubation time of 60 minutes, in monolayer of haemolymph. 


\section{Spherulocytes}

Spherulocytes are large cells $(15-35 \mu \mathrm{m})$ with irregular in shape (Figure 1-(L)). The cytoplasm was characteristically filled with a small number of prominent spherules (large inclusions). These cells were scarce in BPH with remaining very low in immature stages. Cell margins may appear rough due to the presence of marginal lumps.

\section{Differential Haemocyte Count}

Result ofone-wayANOVAshowed the statistically significance on PRs among the different stages of the life cycle of BPH (Table 01). Last nympal stadium of BPH possessed a significantly high number of PRs than both sexes of aged adults. While, there are no significant difference, the number of PRs was observed between last nympal and newly emerged adult stages and the mean number of PRs are significantly lower in aged adults than newly emerged ones, but there were no significant differences between the male and female insect.

Mean numbers of two different morphotypes of PLs, GRs and SPs did not show any significant differences with comparison of age groups or sexes as determined by Tukey post-hoc test at 0.05 probability level. The SPs were numerically less abundant in all age categories. Mean number of ADs were significantly high in aged adults compared to other life stages and the percentage increased from $3.9 \pm 0.4$ to $12.5 \pm 3.0$ in females and $7.0 \pm 2.4$ to $14.5 \pm 3.0$ in males with the maturity of adult stage. There was a statistically high number of OEs in aged adults $(5.5 \%$ and $4.5 \%$ for both female and male respectively) compared to nympal and newly emerged adults female at $\mathrm{P} \leq 0.05$ level. The mean number of OEs in adult males was not significantly different at newly emerged adult male at $\mathrm{P} \leq 0.05$ level. But, the mean number of OEs in adult females was significantly higher than both sexes of newly emerged adults at $\mathrm{P} \leq 0.05$ level (Table 01).

\section{'Total Haemocyte Population'}

One-way ANOVA reported in Table 02 shows a statistical difference of total circulating haemocytes among the different age categories of BPHs. A Tukey post-hoc test revealed that the total haemocyte count of nymphs was significantly higher $(7101 \pm 192.399, P=.002)$ than newly emerged males (6096.40 \pm 135.228$)$. Mature adult females possessed a significantly higher number of circulating haemocytes (7393.60 \pm 575.366$)$ than both sexes of newly emerged stage; female $(6600.60 \pm 272.762, P=.013)$ and male $(6096.40 \pm 302.379, P=.000)$ while aged adult male possessed (7119.40 \pm 566.857$)$ a significantly higher amount compared to newly emerged adult male $(P=.001)$ only.

Table 01: Differential haemocyle count of Rice brown plant hopper; Nilaparvata lugens Stål (Hemiptera: Delphacidae) in relation to mean number of cells out of 200 cells

\begin{tabular}{|c|c|c|c|c|c|c|c|}
\hline \multirow{2}{*}{$\begin{array}{c}\text { Life } \\
\text { Stages }\end{array}$} & \multicolumn{7}{|c|}{$\%$ of Cell types (mean \pm StDev) } \\
\hline & $\begin{array}{c}\text { PRs } \\
\text { Mean } \pm \text { sd }\end{array}$ & $\begin{array}{c}\text { PLs-1 } \\
\text { Mean } \pm \text { sd }\end{array}$ & $\begin{array}{c}\text { PLs-2 } \\
\text { Mean } \pm \text { sd }\end{array}$ & $\begin{array}{c}\text { GRs } \\
\text { Mean } \pm \text { sd }\end{array}$ & $\begin{array}{c}\text { ADs } \\
\text { Mean } \pm \text { sd }\end{array}$ & $\begin{array}{c}\text { OEs } \\
\text { Mean } \pm \text { sd }\end{array}$ & $\begin{array}{c}\text { SPs } \\
\text { Mean } \pm \text { sd }\end{array}$ \\
\hline $\mathrm{N}$ & $26.7 \pm 2.1^{\text {a }}$ & $13.2 \pm 1.0^{\mathrm{a}}$ & $22.8 \pm 2.3^{\mathrm{a}}$ & $28.5 \pm 3.6^{\mathrm{a}}$ & $7.0 \pm 1.4^{\mathrm{a}}$ & $1.5 \pm 0.7^{\mathrm{a}}$ & $0.3 \pm 0.4^{\mathrm{a}}$ \\
\hline NEA 9 & $32.5 \pm 4.3^{\text {a }}$ & $12.3 \pm 2.5^{\mathrm{a}}$ & $22.0 \pm 3.9^{\mathrm{a}}$ & $26.6 \pm 2.2^{\mathrm{a}}$ & $3.9 \pm 0.4^{\text {a }}$ & $1.5 \pm 0.7^{\mathrm{a}}$ & $0.7 \pm 0.5^{\mathrm{a}}$ \\
\hline NEA ${ }^{\circ}$ & $30.5 \pm 2.2^{\text {a }}$ & $12.4 \pm 1.5^{\mathrm{a}}$ & $21.6 \pm 2.4^{\mathrm{a}}$ & $25.0 \pm 5.9^{\mathrm{a}}$ & $7.0 \pm 2.4^{\text {a }}$ & $2.5 \pm 1.4^{\mathrm{ab}}$ & $1.0 \pm 0.7^{\mathrm{a}}$ \\
\hline $\mathrm{A}$ 우 & $18.0 \pm 2.3^{b}$ & $13.5 \pm 1.6^{\mathrm{a}}$ & $21.5 \pm 1.4^{\mathrm{a}}$ & $28.4 \pm 5.6^{\mathrm{a}}$ & $12.5 \pm 3.0^{b}$ & $5.5 \pm 1.6^{\mathrm{c}}$ & $0.6 \pm 0.6^{\mathrm{a}}$ \\
\hline $\mathrm{A} \mathrm{O}^{\lambda}$ & $16.5 \pm 3.8^{b}$ & $12.6 \pm 2.3^{\text {a }}$ & $20.9 \pm 2.3^{\mathrm{a}}$ & $30.0 \pm 3.3^{\text {a }}$ & $14.5 \pm 3.0^{b}$ & $4.5 \pm 0.9 \mathrm{bc}$ & $1.0 \pm 0.5^{\mathrm{a}}$ \\
\hline
\end{tabular}

Values within a given column not followed by the same superscript letter are significantly different at 0.05 probability level as determined by tukey's. HSD. PLs-1 - Round shape PLs; PLs-2 - Fusiform shape PLs. N-Nymph; NEA

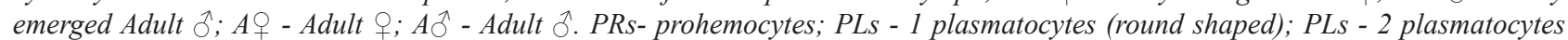
(fusiform shaped); GRs-granulocytes; ADs-adipohemocytes; OEs-oenocytoids; Sps-spherulocytes. 
Total Circulating Haemocytes of Rice brown plant hopper; Nilaparvata lugens Stål (Hemiptera: Delphacidae) per cubic millimeter $\left(\mathrm{mm}^{3}\right)$ of haemolymph.

\begin{tabular}{|c|c|c|c|c|}
\hline \multirow{2}{*}{ Life stages } & \multirow{2}{*}{ Mean $\pm \mathrm{SD}$} & \multirow{2}{*}{ Std. Error } & \multicolumn{2}{|c|}{$95 \%$ Confidence Interval for Mean } \\
\hline & & & Lower Bound & Upper Bound \\
\hline Nymph & $7101.0 \pm 192.3^{\mathrm{bc}}$ & 86.044 & 6862.10 & 7339.90 \\
\hline Newly emerged Adult $q$ & $6600.6 \pm 272.7$ ab & 121.983 & 6261.92 & 6939.28 \\
\hline Newly emerged Adult $\widehat{\jmath}$ & $6096.4 \pm 302.3^{\text {a }}$ & 135.228 & 5720.95 & 6471.85 \\
\hline Adult $q$ & $7393.6 \pm 575.3^{c}$ & 257.311 & 6679.19 & 8108.01 \\
\hline Adult $\widehat{o}$ & $7119.4 \pm 261.7 \mathrm{bc}$ & 117.053 & 6794.41 & 7444.39 \\
\hline
\end{tabular}

Values followed by the same superscript letter in the column are statistically not different at the .05 level as determined by Tukey HSD $(P<0.05)$.

Numerous works on the classification of insect haemocytes by using light microscopic observations in different group of insects have been published with remarkable differences of opinions concerning haemocyte classifications and terminologies. Types of haemocytes identified in insects are not always present in all species (Wigglesworth, 1959; Jones, 1962; Price and Ratcliffe, 1974; Sahayarij et al., 2007; Josef and Klara, 2008) and there is an inherent variability of haemocytes within a species as well as among closely related species (Price and Ratcliffe, 1974). Therefore, classification of insect haemocytes is the subject of controversy, and the terminology used to assign each cellular type is often different from one species to another.

In this experiment, we did not observe surface projections (pseudopodia) of GRs of BPH when these cells spread out on the glass surface. These observations are in accordance as well as differ with some previous findings. With the accordance with many previous studies of different kinds of insects, PLs of BPH showed many surface projections (pseudopodia). For an example, in 1974, Price and Ratcliffe observed blood films of fifteen insect orders and according to their viewed GRs might be existed with or without surface projections and PLs begun to spread out after bleeding with forming surface projections in many insect orders. Prominent lipid-like inclusions in the cytoplasm of ADs are characteristic to many other insects (Sanjayan, et. al., 1996; Silva, et. al., 2002; Lea and Gilbert, 1966; Fevzi and
Olga, 2010). Similar to the OEs of some other insects like Spodoptera litura (Kurihara et al., 1992), and Pseudoplusia includens (Strand and Noda, 1991), OEs of BPH also underwent rapid lysis after bleeding. SPs in BPH are haemocytes exhibiting large inclusions in cytoplasm. Their characteristics are similar to those observed in other insect species (Miyuki and Kikuo, 2001; Brayner et al., 2005). PRs are believed to be the basic stem-type cells that divide frequently and give rise to other types of haemocytes (Suhail et al., 2007). In the present study, the percentage of pohaemocytes decreased while increasing the THC with their maturity also shows the greater transformation of pohaemocytes into other type of cells.

There are no available data to compare the different types of haemocytes of BPH with other delphacid of order homoptera. There are few published data of different types of haemocytes of the same order, but, comparing different types of haemocytes within the order is not ideal. Similar to the Agallia constricta, the BPH has PRs, PLs, GRs, ADs, OEs and SPs (Granados \& Meehan 1973). Haemocyte profile of Spilostethus hospes showed PRs, PLs, Grs, ADs and SPs (Sanjayan et al., 1996). According to the Patro et al. (2005), five types of haemocytes were found in the haemolymph of Aphis gossypii, namely PRs, PLs, spindle shaped haemocytes, GRs and ADs. Furthermore, his study clearly pointed out 
that the spindle shaped haemocytes is a kind of plasmatocytes. However, PRs, OEs, and GRs were observed in Phenacoccus manihot and only GRs were observed in Planococcus citri by Russo et al. (1994). Four (4) distinct types of haemocytes : PRs, GRs, PLs, and SPs were identified in the Pyrrhocoris apterus by Josef and Klara (2008).

The changes in both, the number of circulating hemocytes and in the relative proportions of different hemocyte types in the hemolymph of insects are a normal response to immune defense. Cellular defense mechanism of insects is primarily depending upon the availability of circulatory hemolymph and the changes on the THC are a good indicator for the activation of the mechanisms of innate immune system of insects. According to Lavine \& Strand (2002), the increases in THC also show the activation of the mechanisms responsible for phagocytosis, nodule formation, encapsulation, recognition of foreign bodies and wound healing. On the other hand, decreases in THC show a decline in the proportion of metabolically active cells which suggests to a reduction of the ability of insects cellular defense system. Therefore, these findings are essential towards the advancement of insect immunological studies. prohemocytes (PRs), plasmatocytes (PLs), granulocytes (GRs), adipohemocytes (ADs), oenocytoids (OEs) and spherulocytes (SPs). It was estimated that the mean numbers of total haemocyte count are varied from 6096.4 to 7393.6 cells per $\mathrm{mm}^{3}$ of haemolymph with the different physiological stages of the insects and it statistically increased in the aged adults. PLs, GRs and PRs are the most abundant cells in the haemolymph in all development stages of BPH while SPs are the scarcest type.

Small size of the BPH with a limited amount of hemolymph was the key challenge to collect hemocyte in this experiment. However, up to date, using different names for the hemocytes often leads to confusing identification and of hemocytes. Therefore, it is important to develop a more uniform terminology for naming insect hemocytes in different insect species. The gap is rapidly closing as more studies on insect hemocytes enter the literature.

To the best of our knowledge, this is the first study to detect the hemocytes of BPH and these data will be important for future immunological research using BPH. However, further studies are needed in order to improve the knowledge on the functional aspects of each hemocyte types in a cellular manner.

\section{CONCLUTIONS}

Examination of hemocytes from BPH indicated the presence of six types of hemocyte:

\section{REFERENCES}

Barracco, M. A. and Cestari, A. N. 1984. Studies on the hemocytes of Trichosia pubescens (Diptera: Sciaridae) larvae. Brazilian Journal of Genetics V1l (3), 451-475.

Brayner, F.A., Araujo, H.R., Cavalcanti, M.G., Alves, L.C. and Peixoto, C.A. 2005. Ultrastructural characterization of the hemocytes of Culex quinquefasciatus (Diptera: Culicidae). Micron 36(4), 359-367.https://doi.org/10.1016/j.micron.2004.11.007

Brehelin, M., Zachary, D. and Hoffman, J. A. 1978. A comparative ultrastructural study of blood cells from nine insect orders. Cell and Tissue Research 195, 45-57. https://doi.org/10.1007/ BF00233676 
Cerenius, L. and Soderhall, K. 2011. Coagulation in Invertebrates. Journal of Innate Immunology 3(1), 3-8. https://doi.org/10.1159/000322066

de Andrade, F. G., de Negreiro, M. C. C., Levy, S. M., Fonseca, B. de I. C., Moscardi, F. and Falleiros, A. M. F. 2010. Hemocyte quantitative changes in Anticarsia gemmatalis (Lepidoptera: Noctuidae) larvae infected by AgMNPV. Brazilian Archives of Biology and Technology 53(2), 279-284.

Dyck, V. A. and Thomas, B. 1979. The brown planthopper problem. In Brown planthopper: threat to rice production in Asia. International Rice Research Institute (ED.), Los Banos, Laguna, Philippines. pp 3-17.

Fevzi, U. and Olga, S. 2010. Cytotoxic Effect of Cypermethrin on Pimpla turionellae (Hymenoptera: Ichneumonidae) Larval Hemocytes. Ekoloji 19 (75), 20-26. https://doi.org/10.5053/ ekoloji.2010.753

Granados, R. R. and Meehan, D. J. 1973. Morphology and differential counts of hemocytes of healthy and wound tumor virus-infected Agalliaconstricta. Journal of Invertebrate Pathology vol. 22 (1) 6069 .

Gupta, A. P. (ed) 1979 c. Arthropod haemocytes and phylogeny; in Arthropode phologeny (Van Nostrand -Reihold, New York) pp 669-735.

Gupta, A. P. (ed) 1979a. Haemocyte types their structure species interrelationship and taxonomic significance; in Insect haemocytes (Cambridge: Cambridge University Press) pp85-127. https:/ doi.org/10.1017/CBO978511759987.005

Gupta, A. P. (ed) 1979b. Identification key for hemocyte types in hanging-drop preparations; in Insect haemocytes (Cambridge: Cambridge University Press) pp 527-530. https:/doi.org/10.1017/ CBO978511759987.018

Gupta, A. P. 1985. Cellular elements in the haemolymph; in comprehensive insect physiology, Biochemistry and Pharmacology (eds) G. A. Kerkut and L. I. Gilbert, Cambridge University Press, Crambridge (1985) 85- 127

Gupta, A. P. 1994. Insect haemocytes: Classification and immunologic functions; in Recent advances in insect physiology and toxicology (ed.) Gujar G. T. (New Delhi: Agricole Publishing Academy) pp 106-206.

Gupta, S., Wang, Y. and Jiang, H. 2005. Purification and characterization of Manduca sexta prophenoloxidase-activating proteinase-1, an enzyme involved in insect immune responses. Protein Expression and Purification 39 (2), 261-268. https://doi.org/10.1016/j.pep.2004.10.011

Hillyer, J. F. and Christensen, B. M. 2002. Characterization of hemocytes from the yellow fever mosquito, Aedes aegypti. Histochemistry and cell Biology 117, 431-440. https://doi.org/10.1007/ s00418-002-0408-0

Jiravanichpaisal, P., Lee, B. L. and Soderhall, K. 2006. Cell-mediated immunity in arthropods: Hematopoiesis, coagulation, melanization and opsonization. Immunobiology 211(4), 213-236. https://doi.org/10.1016/j.imbio.2005.10.015

Jones, J. C. 1962. Current concepts concerning insect hemocytes. Amer. Zool 2, 209-246. https://doi. org/10.1093/icb/2.2.209

Josef, B. and Klara, S. 2008. Morphological Characterization of Hemocytes in the Adult Linden Bug, Pyrrhocoris apterus (L.) (Heteroptera). Zoological Studies 47(4), 466-472. 
Kanost, M.R., Jiang, H. and Yu X.Q. 2004. Innate immune responses of a lepidopteran insect Manduca sexta. Immunological Review 198, 97-105. https://doi.org/10.1111/j.0105-2896.2004.0121.x

Kurihara, Y. Shimazu, T. and Wago, H. 1992. Classification of hemocytes in common cutworm, Spodoptera llitura (Lepidoptera: Noctudae). II. Possible roles of granular plasmatocytes and oenocytiodes in the cellular defense reactions. Applied Entomology and Zoology 27 (2), 225235. https://doi.org/10.1303/aez.27.237

Lai, S., Chen, C. and Hou, R. F. 2001. Electron Microscopic Observations on Wound-Healing in Larvae of the Mosquito Armigeres subalbatus (Diptera: Culicidae). Journal of Medical Entomology 38(6), 836-843. https://doi.org/10.1603/0022-2585-38.6.836

Lavine, M. D. and Strand, M. R. 2002. Insect haemocytes and their role in immunity. Insect Biochemistry and Molecular Biology 32, 1295-1309. https://doi.org/10.1016/S0965-1748(02)00092-9

Lea, M. S. and Gilbert, L. I. 1966. The hemocytes of Hyalophora cecropia (Lepidoptera). Journal of Morphology 118 (2), 197-215. https://doi.org/10.1002/jmor.1051180205

Mangalika, R. P., Kawamoto, T., Takahashi-Nakaguchi, A. and Iwabuchi K. 2010. Characterization of cell clusters in larval hemolymph of the cabbage armyworm Mamestra brassicae and their role in maintenance of hemocyte populations. Journal of Insect Physiology 56, 314-323. https://doi. org/10.1016/j.jinsphys.2009.11.003

Meloni, S., Mazzini, M. and Scapigliati, G. 1999. Ontogenesis of hemocytes in the stick insect Bacillus rossius (Rossi) (Phasmatodea, Bacillidae) studied with an anti-hemocyte monoclonal antibody. International Journal of Insect Morphology and Embryology 28(3), 247-252. https:// doi.org/10.1016/S0020-7322(99)00020-3

Miyuki, Y. and Kikuo, I. 2001. Bombyx mori prohemocyte division and differentiation in individual microcultures. Journal of insect physiology 47(4-5), 325-331. https://doi.org/10.1016/s00221910(00)00144-X

Pandey, J. P. and Tiwari, R. K. 2012. An Overview of Insect Hemocyte Science and its Future Application in Applied and Biomedical Fields. American Journal of Biochemistry and Molecular Biology 2, 82-105. https://doi.org/10.3923/ajbmb.2012.82.105

Pandey, J. P., Mishra, P. K., Kumar, D., Singh, B. M. K. and Prasad, B. C. 2010. Effect of Temperature on Hemocytic immune responses of Tropical Tasar Silkworm, Antherare mylitta D. Research Journal of Immunology 3(2), 169 -177. https://doi.org/10.3923/rji.2010.169.177

Patro, B., Komazaki, S. and Toda, S. 2005. Studies on the heamocytes of Aphis gossypii Glover (Aphididae: Homoptera). Indian Journal of Agricultural Research, 39 (3) 192-197.

Patton, R. L. 1961. The detoxication function of insect haemocytes, Annals of Entomological Society of America, Baltimore 54(5), 696-698. https://doi.org/10.1093/aesa/54.5.696

Price, C. D. and Ratcliffe, N. A. 1974. A reappraisal of insect haemocyte classification by the examination of blood from fifteen insect orders. Cell and Tissue Research 147 (4), https://doi. org/537-549. 10.1007/BF00307254

Qamar, A. and Jamal, K. 2009. Differential haemocyte counts of 5th instar nymphs and adults of Dysdercus cingulatus Fabr (Hemiptera: Pyrrhocoridae) treated with acephate, an organophosphorus insecticide. Biology and Medicine 1 (2), 116-121. 
Ratcliffe, N.A., Rowley, A.F., Fitzgerald, S.W. and Rhodes, C.P. 1985. Invertebrate Immunity: Basic Concepts and Resent Advance. International Review of Cytology 97, 183-350. https://doi. org/10.1016/S0074-7696(08)62351-7

Ribeiro, C., and Brehelin, M. 2006. Insect haemocytes: What type of cell is that? Journal of Insect Physiology 52(5), 417- 429. https://doi.org/10.1016/j.jinsphys.2006.01.005

Rowley, A. F. and Powell A. 2007. Invertebrate Immune System - Specific, Quasi-Specific, or Nonspecific? Journal of Immunology 179, 7209-7214. https://doi.org/10.4049/ jimmunol.179.11.7209

Russo, J., Allo, M.R., Nenon, J.P. and Brehelin, M. 1994. The hemocytes of the mealybugs Phenacoccus manihoti and Planococcus citri (Insecta: Homoptera) and their role in capsule formation. Canadian Journal of Zoology 72(2), 252-258,

Sahayarij, K., Selvarj, P. and Balasubramanian, R. 2007. Cell mediated immune response of Helicoverpa armigera hubner and Spodoptera litura fabricius to fern phytoecdysteron. Journal of Entomology 4(4), 289-298. https://doi.org/10.3923/je.2007.289.298

Sanjayan, K.P.; Ravikumar, T. and Albert, S. 1996. Changes in the haemocyte profile of Spilostethus hospes (Fab) (Heteroptera: Lygaeidae) in relation to eclosion, sex and mating. Journal of Bioscience 21(6), 781-788.https://doi.org/10.1007/BF02704719

Shrestha, S., Park, Y., Stanley, D. and Kim, Y. 2010. Genes encoding phospholipases A2 mediate insect nodulation reactions to bacterial challenge. Journal of Insect Physiology 56, 324-332. https://doi.org/10.1016/j.jinsphys.2009.11.008

Silva, J. E. B., Boleli, I.C. and Simoes, Z. L. P. 2002. Hemocyte types and total and differential counts in unparasitized and parasitized Anastrepha obliqua (Diptera, Tephritidae) larvae. Brazilian Journal of Biology 62 (4), 689-699. https://doi.org/10.1590/s1519-69842002000400017

Stand, M. R. 2008. The insect cellular immune response. Insect Science 15, 1-14 https://doi. org/10.1111/j.1744-7917.2008.00183.x

Strand, M.R. and Noda T. 1991. Alterations in the haemocytes of Pseudoplusia includens after parasitism by Microplitis demolitor. Journal of Insect Physiology 37 (11), 839-850.

Suhail, A., Gogi, M. D., Arif, M. J., Arshad, M., Rana and Sarfraz, M. 2007. Effect of various treatments of azadirachtin, spinosad and abamectin on the haemogram of Coccinella septempunctata L. (Coleoptera: coccinellidae). Pakistan journal of Entomology 29 (2), 151.https://doi. org/10.1603/0022-0493(2007)100[411:eoaaas]2.0.co;2

Wang, Z., Lu, A., Li, X., Shao, Q., Beerntsen, B. T., Liu, C., Ma, Y., Huang, Y., Zhu,H. and Ling, E. 2011. A systematic study on hemocyte identification and plasma prophenoloxidase from Culex pipiens quinquefasciatus at different developmental stages. Experimental Parasitology 127(1), 135-141. https://doi.org/10.1016/j.exppara.2010.07.005

Wigglesworth, V. B. 1959. Insect Blood Cells. Annual Review of Entomology 4, 1-16. https://doi. org/10.1146/annurev.en.04.010159.000245

Win, S.S., Muhamad, R. Ahmad, Z.A.M. and Adam, N.A. 2011. Population Fluctuations of Brown Plant Hopper Nilaparvata lugens Stal. And White Backed Plant Hopper Sogatella furcifera Horvath on Rice. Journal of Entomology 8, 183-190.https://doi.org/10.3923/je.2011.183.190 